\title{
Küresel Keynesçilik Yaklaşımı Bağlamında Küresel Maliye Politikaları
}

Global Finance Policies in the Context of Global Keynesian Approach

Mustafa Alpin GÜLŞEN ${ }^{1}$, Ali Gökhan GÖLÇEK ${ }^{2}$

Article Info

\begin{tabular}{l}
\hline Article History: \\
Date Submitted: 30.07 .2019 \\
Date Accepted: 01.08.2019 \\
Jel Classification \\
F62, E62, E21 \\
Keywords: \\
Global Keynesianism, \\
Global Finance Policies, \\
Global Welfare
\end{tabular}

Abstract

This study is written to reveal the global Keynesian economic approach, which is a revision of the classical Keynesian approach to that of today. Accordingly, the global Keynesian approach consists of policy proposals such as global income, global money, and global income distribution, which will make the most inefficiency in global demand less. These policy instruments are a solution to the inadequacy of demand for global economic activity through a mechanism created by the public sector.

\section{Özet}

$\mathrm{Bu}$ çalışma Klasik Keynesyen yaklaşımın, günümüzün koşullarına göre revize edilmiş bir yaklaşım olan Küresel Keynesyen iktisadi anlayışını ortaya koymak amacıyla yazılmıştır. Buna göre Küresel Keynesçilik yaklaşımı, küresel talep yetersizliğini en aza indirecek küresel gelir, küresel para ve küresel gelir dağılımı gibi politika önermelerinden oluşmaktadır. $\mathrm{Bu}$ politika araçları, kamu kesimi tarafından oluşturulacak bir mekanizma ile küresel ekonomik faaliyette meydana gelen talep yetersizliği sorununa çözüm olmaktadır.

\section{Giriş}

Küreselleşme ile birlikte, iktisadi yaklaşımların kamu kesimi ile piyasa arasına çizdiği sınırda önemli değişimler meydana gelmiştir. Günümüzde neoliberalizm ile anılan küreselleşme olgusunun da kullanım alanı bu sürede değişme ve genişleme göstermiştir. Bu açıdan 19. ve 20. yüzy1llarda, kendi kendini düzenleyen piyasalara yönelik hareketin ortaya negatif etkiler çıkarttı̆̆ iddiasıyla, 21. Yüzyılda Küresel Keynesçilik bağlamında bir karşı hareket ortaya çıkmıştır (Patomäki, 2009: 442).

\footnotetext{
${ }^{1}$ Öğr. Gör., Akdeniz Üniversitesi, Kumluca MYO, Finans Bankacılık ve Sigortacılık Bölümü, m.alpingulsen@gmail.com, ORCID: 0000-0002-2860-4469.

${ }^{2}$ Arş. Gör., Niğde Ömer Halisdemir Üniversitesi, İIBF, Maliye Bölümü, aligokhangolcek@gmail.com, ORCID: 0000-0002-7948-7688.
} 
Klasik Keynesyen teorinin ulusal sınırlarının Keynes tarafından çizilmesinin ardından, PostKeynesyen bir yaklaşımla ele alan Kalecki'nin genişletmesiyle Keynesyen yaklaşım tekil bir ulusun ötesine geçmeye başlamıştır. Kapalı ekonomilerin artık olmadığı günümüzde iktisadi yaklaşımlar zorunlu olarak küreselleşme olgusunu da analizlerine dahil etmektedir. Böyle bir perspektif, kapsamı sınırlı olsa da 1970’lerde J. Tobin tarafindan finansal piyasalardaki kırılganlığı azaltmak amacıyla küresel bir vergi önerisi konularak Keynesyen yaklaşım da küresel bir boyut kazanmıştır. Bununla birlikte günümüzde Küresel Keynesçilik konusundaki tartışmalar Tobin'in oldukça ötesine geçmiştir. Örneğin, sadece devletler arasındaki ekonomik politikaların koordinasyonu, karşılıklı bağımlılık yönetiminin sürdürülebilir kılınması için yeterli değildir (Patomäki, 2013). Bu açıdan Keynesyen perspektiften küresel krizlerin de bir çözümü olarak küresel talebin artırılması önerilmektedir. Ancak Küresel Keynesçilik fikrinin günümüzde ekonomik sistem ile doğrudan çeliştiği de ifade edilmektedir. Buna göre mevcut sistemde yeni pazarlar ve ucuz işgücü gibi dengesizlikler ile sermaye birikiminin sağlandığ 1 ve böyle bir birikim sürecinin Küresel Keynesçilik ile ortadan kalkacağı ifade edilmektedir (Bieler, 2013). Ek olarak uluslararası kapitalist devlet sisteminin sadece kurumsal değil, aynı zamanda ekonomik ve politik rekabete dayanması nedeniyle, küresek Keynesçilik yaklaşımının reel hayatta uygulanmasının imkânsız olduğu da vurgulanmaktadır (Brand, 2006: 245).

Küresel Keynesçilik, dikkatleri gelişmemiş ülkelere çekerek demokratik denetime tabi olmayan kurumlara şeffaflık ve hesap verebilirliğin getirilmesi; temel emtia ihracatının tam değeri ile yapılması ve küresel sisteme sağladıkları pozitif dışsallıktan dolayı ekolojik hizmetler için para ödemek; şirketlerin tekel gücünü azaltmak için küresel kuralların koyulması; ülkelerin iflas beyan etmelerine izin vererek borçların koşulsuz affını sağlamak ve Keynes tarafından öne sürülen, ihtiyacı olanlara borç veren küresel bir bankanın kurulmasına yönelik politikaları ön plana çıkarmıştır (Sheppard ve Leitner, 2010: 189).

Ancak günümüzde Küresel Keynesçilik fikrinin uygulamaya geçmesi oldukça uzak bir ihtimal olarak görülmektedir. Çok uluslu (çıkar grupları) bankaların ve şirketlerin yoğun baskısı altında politika yapıcılarının, para ve finansal piyasalardaki kontrolünü kaybetmesi nedeniyle başta kurum vergileri olmak üzere mali yükleri hafifletmek zorunda kaldığı ifade edilmektedir. Bu açıdan kısa vadeli spekülatif sermaye hareketleri ve bunların mali kırılganlıklara neden olması, hükümetleri artık kendi iç ekonomilerini düzenleme özgürlüğüne sahip olmadığını da göstermektedir (Paul, 1996). 
$\mathrm{Bu}$ gelişmeler çerçevesinde çalışmada, Küresel Keynesçilik yaklaşımının kamu yönetimi ve siyaset bilimi literatüründeki rolü ele alınmayacak olup iktisadi açıdan getirdiği yenilikler ve temel argümanları ele alınacaktır. Çalışmada öncelikle söz konusu kavramın genel olarak ne ifade ettiği üzerinde durulacak ve Küresel Keynesçilik yaklaşımının hedeflerine ve politika önermelerine değinilecektir. Çalışmanın odak noktasını ise, Küresel Keynesçilik yaklaşımının politika hedeflerinden hareketle, küresel maliye politikalarındaki konumu oluşturmaktadır. Çalışmada küresel Keynesyen bir yaklaşımın uygulanması durumunda olası bir maliye politikası aktarım mekanizmasının nasıl olduğu hususu açıklandıktan sonra, çalışma sonuç bölümüyle sonlandırılacaktır.

\section{Kavramsal Çerçeve}

Küresel Keynesçilik ile ilgili tanımlara literatürde ulaşmak her ne kadar zor olsa da genel olarak, bir küresel sistem bağlamında iktisadi sorunların sorumluluğunu üstlenen bir kamu yönetimini vurgulayan iktisadi yaklaşım olarak ifade edilebilir. Ek olarak küresel Keynesyen yaklaşımın ilgilendiği konular kamu yönetimi, demokratik siyaset, karma ekonomi, küresel gelir dağılımı, küresel yatırım, küresel para ve küresel talebin yönetimi, ekolojik sürdürülebilirlik ve yerel, ulusal ve uluslararası açıdan çok katmanlı kamu yönetimi olarak sıralanmaktadır. Küresel Keynesçilik, küresel neoliberalizm ${ }^{3}$ yaklaşımına alternatif olarak bahsedilmekte ancak söz konusu kavramın tanımı ve çerçevesi ile ilgili olarak bir sınır belirlemek oldukça zor olmaktadır. İlk kez 1980'li yılların başında literatüre giren ve uluslararası Keynesçilik de denilen Küresel Keynesçilik kavramı, bu dönemde Brandt Raporu'nu tanımlamak amacıyla kullanılmıştır (Köhler, 1999a: 253).

Diğer taraftan Küresel Keynesçilik kavramını iktisadi hususlarla ilişkilendirilmesinde iktisatçı J. K. Galbraith'in önemli katkılarının olduğu söylenebilir (Arslan, 2010: 1232). Galbraith (1995: 69)'e göre Küresel Keynesyenizm terimi yüksek ekonomik büyüme ve istihdam, yaşam standardının küresel açıdan yükselmesi ve yüksek ekonomik büyümeyle birlikte minimum mali istikrarsızlığın sağlanmasına imkân tanıyacak küresel açıdan ülkelerin birbirine bağımlı olduğu bir yönetim mekanizmasını ifade eder.

\footnotetext{
${ }^{3}$ Küresel neoliberalizm, 1970'li yıllarda devletin ekonomideki rolünün azaltılması ve aynı zamanda şeffaflığının ve hesap verilebilirliğinin (iyi yönetişim) artmasına yönelik olarak, Dünya bankası ve IMF gibi Bretton Woods kurumlarının sıklıkla önerdiği politikalar bütüne olarak ifade edilebilir (Demmers vd., 2004: 1)

${ }^{4}$ Brandt Raporu, 1980'li yıllarda Almanya başbakanı W.Brandt tarafından ortaya atılan ve kısaca, Dünya bankası aracılığıyla gelişmiş ülkelerin gelişmemiş ülkelere yardım etmesini öneren rapordur (Hayter, 1983:6-7).
} 
Söz konusu kavramın ortaya çıkışı ve tanımlarından hareketle küresel Keynesçiliğin, bir bütün olarak ülkelerin ekonomik büyümesini, tam istihdamını ve mali kırılganlığının en aza indirilmesini sağlayacak bir mekanizmanın oluşturulması ve böylece yine küresel açıdan yaşam standartlarının yükselmesine yönelik bir politikalar demeti olarak ifade etmek mümkün gözükmektedir. Söz konusu hedeflere ulaşılmasında ise Küresel Keynesçilik ile ilgili iktisadi literatürü oluşturan ve çalışmanın kapsamında bulunan küresel gelir dağılımı, küresel yatırım, küresel para ve küresel talebin yönetimi gibi kavramlar ön plana çıkmaktadır.

\subsection{Küresel Talep ve Küresel Arz}

Küresel talep, tek bir ülkenin ekonomisindeki talep miktarının aksine dünya ekonomisindeki toplam efektif talep miktarını ifade etmektedir. Söz konusu kavram, küresel iktisadi gelişmelerin geçmişi ve geleceği hakkında çıkarımlar yapmamıza imkân tanımaktadır (Köhler, 1998a). Bu açıdan küresel talebin yetersizliği özellikle uluslararası şirketlerin ve üretim yapan ülkelerin yatırım kararlarını; bir diğer ifadeyle küresel ekonomiye yönelik beklentilerini etkileyecek önemli bir unsur olmaktadır.

Köhler (1998a)'e göre, Keynesyen akım açısından son derece önemli olan küresel talep yetersizliği sorunu iki farklı biçimde ortaya çıkmaktadır: İlk olarak emek piyasasında yer alan çalışanların ya da küresel işgücünün makul bir hayat standardı için yeterli bir satın alma gücünün yokluğu olarak ortaya çıkmaktadır. $\mathrm{Bu}$ açıdan yetersiz küresel talep, tüm insanlar tarafından gözlemlenen ve değerlendirilebilen bir "mutlak" yetersizliği ifade etmektedir. İkinci olarak küresel talebin yetersizliği "göreceli” olarak ele alınmaktadır. Küresel arz (toplam üretim gücü) ile küresel talep (toplam satın alma gücü) arasında yer alacak olası bir talep aralığı (açığı), dünya ekonomisinin dolaşım akışında önemli bir husus olarak görülmektedir. Söz konusu talep açığı alternatif olarak, aşırı üretim veya yetersiz talep sorununun farklı analitik ve politik vurgularını yansıtan bir sorun olarak ele alınmaktadır Küresel talep yetersizliği ile ilgili bu iki yaklaşımdan hangisinin öncelikli olduğu küresel ekonomik yapının konjonktürüne ve bir başka açıdan küresel ekonomik gelişmeleri hangi iktisadi düşüncenin açısından incelendiğine göre değişiklik gösterecektir. Bu açıdan ilk olarak, üretimin hızla yükseldiği bir konjonktürde küresel talebin yetersiz olma ihtimalinin oldukça yüksek olacağı söylenebilir. Dolayısıyla küresel üretimin küresel tüketimden hızlı artması, küresel talep yetersizliği olarak ifade edilebileceği gibi küresel arzın aşırı artması nedeniyle oluşacak bir arz fazlasını da ifade edebilir. Piyasa ekonomisinin fiyat mekanizması ile belirlenen piyasa talep ve arz dengesini 
küresel açıdan, küresel piyasa dengesini sağlayacak küresel talebe uygun küresel arzın da burada önemli olduğu düşünülmektedir. Diğer taraftan söz konusu arz fazlası, talep açığı olarak yorumlandığında, efektif talebi artıracak maliye politikalarının önerilmesi de olası gözükmektedir. Dolayısıyla küresel talep yetersizliğinin "göreceli” olarak ele alınmasından ziyade "mutlak "olarak görülmesi, özellikle konjonktür karşıtı maliye politikalarının daha etkin harekete geçirilmesine neden olabilir.

\subsection{Küresel Gelir ve Küresel Para}

Küresel gelir, tüm ülkelerin oluşturduğu küresel toplam geliri veya toplam üretimi ifade etmektedir. Bu tanımdan hareketle küresel gelirin, küresel GSYİH ile ölçülmesi mümkündür. Küresel para ise çeşitli boyutlara ve bileşenlere sahip olarak ifade edilebilir. Söz konusu uluslar üstü para toplamları (Mt), küresel paraların toplamı (hacmi) $(\mathrm{Mg})$, tüm ulusal para birimi büyüklüklerinin (Mn) toplamı olarak ifade edilebilir. Söz konusu toplam kısaca, $\mathrm{Mg}=\mathrm{Mn}+\mathrm{Mt}$ olarak formüle edilebilir. $\mathrm{Bu}$ açıdan küresel paranın bileşenleri ise çeşitli şekillerde gösterilebilir: (a) ulusal para birimi- dolar, yuan, peso vb. (b) likidite derecesine göre- nakit, kredi, varlık (c) meşruiyetle: devlet tarafından onaylanmış (yasal ihale), resmi olmayan; (d) değerleme yoluyla- nominal ve gerçek (e) işlevsellik yoluyla- ödeme aracı olarak küresel para veya efektif talep olarak küresel para veya sermaye olarak küresel paradır. Kısacası efektif talep haline gelebilen ve mal ve hizmetlere harcanan küresel paranın, küresel ekonominin dolaşım sisteminde birtakım sızıntıları da bulunmaktadır. Efektif küresel talebin sızıntıları, (a) yastık altı para diye ifade edilen kayıt dışı (gizli) paralar, (b) yerli veya yabancı banka hesaplarında biriken banka bakiyeleri (örneğin, İsviçre bankası hesapları), (c) hükümetler tarafından toplanan ve kamu harcamaları yoluyla ekonomiye geri aktarılmayan fakat kamu borcunu ödemek için kullanılan vergiler, (d) üretken yatırım yerine finansal yatırımlar (sermaye harcamaları) olarak sıralanabilir (Köhler, 1998a; Köhler 1999b).

Küresel Keynesçilik yaklaşımı bağlamında küresel paranın önemi, küresel talep ve küresel refahın artırılmasındaki yerinin öneminden kaynaklanmaktadır. $\mathrm{Bu}$ açıdan ülkelerin para birimleri arasındaki değer farkı ve bu farktan dolayı kaynaklanan adaletsiz para takasları küresel talebin ve refahın artırılmasının önünde önemli bir engel olarak görülmektedir. Buna göre tekil ülke para birimlerinin homojen bir yapıda olmaması, özellikle düşük gelirli ülkelerin para birimlerinin genellikle değer düşüklüğü eğiliminde olması, yüksek ücretli ülkelerin düşük ücretli ülkelerden “döviz kuru sistemi” aracılığıyla değer yaratması ve böylece çevre ve merkez 
ülkeler arasındaki eşitsiz değişime önemli ölçüde etkide bulunmaktadır (Köhler, 1998b: 145). $\mathrm{Bu}$ açıdan küresel gelirin de rasyonel biçimde ölçülebilmesi paranın, küresel bir yapıya kavuşturulmasıyla mümkün olacağı ifade edilebilir. Bir diğer ifadeyle döviz kuru sistemiyle değişim, (para takası aracılığıyla) eşitsiz gerçekleşmektedir. Böylece gelişmiş ülkeler ile gelişmemiş ülkeler arasında başta emek olmak üzere üretim faktörlerinin fiyatlarının, güçlü para biriminin lehine olacak şekilde düşük değerde olması, söz konusu ülke gruplarının gelişmişlik farklılıklarını negatif yönde etkilemektedir. Söz konusu eşitsiz değişim (üretim faktörlerinin alışverişi) ancak küresel bir para biriminin oluşturulmasıyla çözüleceği ileri sürülmektedir.

\subsection{Küresel İşsizlik ve İstihdam}

Keynesyen yaklaşımın, ekonomik sistemdeki bir talep açığının istihdamı negatif yönde etkileyeceğine dair analizi Küresel Keynesçilik yaklaşımda, küresel düzeyde bir analizde uygulanmakta; bu ise küresel istihdam dengesi kavramıyla açıklanmaktadır. Tüm ulus devletlerin ya da tüm ulusal ekonomilerin tekil istihdam dengesi, toplamda küresel istihdam dengesini oluşturmaktadır. Böylece küresel istihdam dengesi bir bütün olarak, tüm ulusal ekonomilerden etkilenmektedir. Bununla birlikte bir ulusal ekonomi, küresel talep açı̆̆ından kaynaklanan örneğin bir küresel işsizlikten doğrudan etkilenerek söz konusu tekil ulusal ekonomide de aynı sorunun olacağı anlamına gelmez. Bir diğer ifadeyle örneğin küresel bir depresyon durumunda tekil ülkelerin bir kısmı bu negatif gelişmeden etkilenmeyebilir.

Günümüzde $\mathrm{ABD}$, OECD ülkelerinin birçoğundan daha düşük bir işsizlik oranına sahip olmakla birlikte OECD ülkeleri, OECD dışı ülkelerden daha az işsizlik ve eksik istihdama da sahiptir. Küresel Keynesçilikte ifade edilen dünya sistemine göre tekil ülkelerin toplam ulusal dengesi, genel küresel dengeden tamamen bağımsız olmamakla birlikte, nispeten daha avantajlı veya dezavantajlı da olması mümkündür. Dolayısıyla küresel denge ile ulusal denge arasındaki aktarım mekanizmaları aracılığıyla küresel düzey ile ulusal düzey arasındaki yoksulluk veya refahın aktarılması, küresel yatırım akışları (finansal ve reel yatırım), küresel ticaret akışları, küresel döviz kuru sistemi, küresel teknoloji transferi, küresel kurumsal regülasyonlar (kuruluşlar, kurallar ve kanunlar) ve son olarak küresel emek hareketliliği gibi mekanizmalarla mümkün olabilir. Bu açıdan küresel talep, toplam ekonomik faaliyetin ve çıtıtların (GSYİH) sınırlarını belirlemektedir. Dolayısıyla küresel talep açığının veya arz açığının büyüklüğü, tam istihdamın seviyesini de belirleyecektir. Bu noktada Küresel Keynesçilik yaklaşımı, küresel 
talep ve arz tarafindan, küresel istihdamda ve dolayısıyla küresel gelirde meydana gelecek bir negatif etkinin sadece geniş bir şekilde tanımlanmış olan kamu müdahalesi (kamu yönetimi) ile bertaraf edileceğini iddia etmektedir (Köhler, 1998a).

$\mathrm{Bu}$ açıklamalardan hareketle klasik Keynesyen yaklaşımda olduğu gibi, Küresel Keynesçilik anlayışında da piyasaların kendi kendine dengeye geleceğini; fiyat mekanizmasının piyasaları temizleyeceğine yönelik neoklasik argümana karşı yine kamu müdahalesi önerilmektedir. Bu açıdan "küresel görünmez el” olarak ifade edilebilecek ve özellikle Bretton Woods kuruluşları tarafından politik önermeleri yapılan küresel neoliberalizm yaklaşımına alternatif olarak Küresel Keynesçilik tarafından küresel regülatörler vasıtasıyla kamu müdahaleleri önerilmektedir.

\section{Küresel Keynesçiliğin Hedefleri}

Köhler (1998a)'e göre, Küresel Keynesçilik yaklaşımı bir iktisadi ekol olması anlamında henüz güçlü bir teorik zemine sahip değildir. Söz konusu bu yeni yaklaşımın temel argümanlarına ek olarak, uzun dönemli iktisadi hedeflerine bakıldığında: (1) küresel tam istihdam; (2) küresel gelir dağılımının iyileştirilmesi; (3) küresel sosyal güvenlik; (4) küresel ekonomik büyüme olarak sıralamak mümkündür.

Klasik Keynesyen anlayışa paralel olarak, Küresel Keynesçi literatür, (1) belirli kategorilerdeki ülkeler için borç hafifletilmesi veya borç affını ve (2) emtia fiyat istikrar planlarını; (3) yüksek gelirli ülkelerden gelen dış yardımları; (4) düşük ve orta gelirli ülkeler için ticaret koşullarının iyileştirilmesi ve kalkınma konusundaki mali ve idari öneri ve yardımları desteklemektedir. Bu açıdan özellikle ulusal mali ve idari unsurların, ulusal veya küresel sermayeye bağımlı olmasını eleştirmekte ve bu ilişkilerin küresel bağlamda yeniden tanımlanmasını önermektedir. Buna paralel olarak emek ile sermaye kesimleri arasındaki toplu pazarlıkların da yeniden gözden geçirilerek kurumsal bir özellik olarak toplu pazarlıkların küresel ölçekte güçlendirilmesini ve korunmasinı savunmaktadir.

Diğer taraftan Küresel Keynesçilik, deregüle edilmiş ve denetlenmesinde önemli sorunlar olan küresel finansal sermayenin üzerindeki kontrollerin artırılmasını desteklemektedir. Bu amaçla, kısa vadeli spekülatif gelişmeleri yavaşlatmak amacıyla özellikle Tobin vergisi önemsenmektedir. Bu açıdan finansal piyasalar yerine reel sektörlere yatırım yapılarak, küresel talebin artırılmasına yönelik küresel kredilerin oluşturulması ve böylece gelişmiş ülkeler ile 
gelişmemiş ülkeler arasındaki farkın kapatılmasıyla küresel gelir dağılımının iyileştirilmiş olacağı savunulmaktadır.

Bununla birlikte günümüzdeki döviz kuru sistemi, küresel talebin dağılımını bozmakta ve eşit olmayan bir değişim ilişkisine neden olmaktadır. Bunun gelir dağılımını negatif yönde etkilemesini engellemek amacıyla örneğin döviz kuru kontrollerine geri dönülmesi veya tek bir küresel para biriminin oluşturulması önerilmektedir.

\section{Küresel Keynesyen Yaklaşımda Maliye Politikasının Konumu}

Keynesyen yaklaşımdan hareketle, küresel Keynesyen anlayışın belirtilen hedeflerine ulaşabilmesi için hangi maliye politikası araçlarını kullanacağı hususunda birtakım önerilerde bulunabilir. Belirtmek gerekir ki, küresel Keynesyen hedeflere ulaşmada somut maliye politikası önerileri, bildiğimiz kadarıyla, literatürde henüz oluşturulmamıştır. Dolayısıyla bu bölümde sunulacak maliye politikaları önerileri, küresel Keynesyen yaklaşımın öne sürdüğü temel argümanlardan yola çıkarak, post-Keynesyen maliye politikası aktarım mekanizması itibarıyla ele alınacaktır. Bu açıdan dar kapsamlı, fakat diğer çalışmalarda sunulacak daha geniş maliye politikası önerilerine muhtemel bir zemin hazırlaması açısından önemli görülebilecek, bir çerçeve oluşturulacaktır. Söz konusu aktarım mekanizmasının oluşturulmasında Fontana'nın (2009: 18) maliye politikası aktarım mekanizmasından yararlanılacaktır.

Küresel Keynesyen yaklaşımın temel hareket noktası, küresel efektif talebi artırarak küresel tam istihdamı ve küresel gelir dağılımındaki eşitliği denge noktasına getirmektedir. Ancak bununla beraber söz konusu denge noktasına ulaşılmasında küresel paranın da önemli bir rolü söz konusudur. Buna göre günümüzde döviz kurları yoluyla meydana gelen eşitsiz değişim, gelişmemiş ülkeler ile gelişmiş ülkeler arasındaki gelişmişlik farkını negatif yönde etkilemektedir. Dolayısıyla kur farklılıklarının olmadığı bir küresel para birimi de belirtilen dengeye ulaşmada önemli bir konuma sahiptir. Bu temel argüman çerçevesinde küresel aktarım mekanizması şöyle ifade edilebilir:

$$
\text { GReg. } \rightarrow(G C+G I+G G) \uparrow \rightarrow G T \downarrow \rightarrow G G D P \uparrow \rightarrow G U N \downarrow \rightarrow\left(Y-Y^{*}\right) \downarrow \rightarrow G g i n i \downarrow \rightarrow G g \uparrow
$$

Küresel ekonomide karşılaşılacak talep yetersizliği durumunda, bu yetersizliği ortadan kaldıracak son merciinin (küresel bir devletin olamayacağından hareketle) küresel bir regülatör 
(GReg.) olduğu varsayılmaktadır. Küresel talebin yetersizliği durumunda regülatör (düzenleyici kurum), küresel efektifi talebi artıracak şekilde doğrudan satın alma yoluna gitmesine ek olarak, küresel vergi indirimleri (GT) gibi küresel talep artışını teşvik edici şekilde düzenlemeler de yapabilmekte; böylece dolaylı olarak küresel talebi artırıcı etkide bulunabilecektir. Bu şekilde oluşacak talep artışı, klasik Keynesyen yaklaşımda olduğu gibi, küresel tüketim ve yatırım harcamaları (sırasıyla $G C$ ve GI) ile tekil ulusal kamu kesimi harcamalarını $(G G)$ artıracaktır. Bununla birlikte söz konusu küresel regülatörün finansman kaynağının ne olacağı hususu, çalışmada da belirtildiği üzere, Küresel Keynesçilik literatüründe belirtilmektedir. Buna göre küresel bir banka veya küresel kredi vasıtasıyla finansman sorunu çözülebilmektedir. Küresel özel ve kamu kesiminin toplam talebinin, küresel bir regülatör tarafından doğrudan efektif talebi artıracak şekilde satın alma yoluna gitmesi veya küresel efektif talebi dolaylı şekilde artıracak vergi indirimleri gibi teşvikler sağlaması sonucunda küresel GSYİH (GGDP) artışı mümkün olacaktır.

Küresel ölçekte uygulanan konjonktür karşıtı genişleyici maliye politikası sonucunda küresel işsizlik (GUN) azalacak ve böylece küresel istihdam dengesi de sağlanmış olacaktır. Buna göre başlangıçta, çalışmada mutlak talep yetersizliği olarak belirtilen durumda, tüketimin azalmasına bağlı olarak üretim girdilerinde önemli bir faktör maliyeti olan işçi giderlerinde artış yaşanmış ve bunun sonucunda küresel istihdam dengesi negatif yönde etkilenmiştir. Ancak daha sonra küresel regülatör tarafından doğrudan veya dolaylı olarak artırılan küresel talep ile birlikte küresel istihdam dengesi pozitif yönlü bir eğilim kazanmıştır. Talep yanlı böyle bir etkinin meydana gelmesiyle birlikte, üretim tarafı da bu gelişmelerden pozitif yönde etkilenmektedir. Küresel talep artışı sonrasında artan küresel istihdamla aynı anda üretim açığı da azalmaktadır $\left(Y-Y^{*}\right)$. Mutlak talep yetersizliğinin azalmasıyla birlikte, çalışmada göreceli talep yetersizliği olarak belirtilen arz fazlası sorunu da küresel talep hususunda etkisini azaltmıştır.

Buraya kadar olan küresel iktisadi faaliyetlerde kullanılan değişim aracının (paranın), küresel para olması nedeniyle, eşitsiz bir değişimin olmadığı varsayılmaktadır. İktisadi aktörlerin ekonomik kararlarını etkilemeyen böyle bir tarafsız paranın olması durumunda küresel gelir dağılımında adalet (Ggini) konusunda önemli iyileştirmeler yapılıış olacaktır. Buna göre mevcut döviz kuru sisteminde, gelişmemiş ülkelerden gelişmiş ülkelere doğru döviz kurları vasıtasıyla aktarılan refah unsurları, küresel bir paranın olması durumunda söz konusu olmayacaktır. Böylece gelir dağılımında adalet pozitif yönde etkilenecek, gelişmiş ülkeler ile gelişmemiş ülkeler arasındaki refah farkı azalacaktır. Değişim ilişkilerinin nispeten daha adil 
olduğu ve küresel işsizliğin de azaldığı böyle bir durumda kişi başına düşen küresel satın alma gücü artmış ve üretim tarafında yaşanan arz fazlası (üretim açığı) sorunu ortadan kalkmış böyle bir küresel ekonomide, küresel büyüme $(G g)$ doğal olarak artış göstermişstir. Sonuç olarak küresel talep yetersizliği sorununa yönelik uygulanan konjonktür karşıtı geniş̧leyici küresel maliye politikası, ekonomideki efektif talebi artırıcı etkide bulunmuştur. Ek olarak, bu işleyişin aksine daraltıcı küresel maliye politikalarının uygulanması durumunda, söz konusu mekanizmanın tersi yönünde politikaların izlenmesi olası görülmektedir.

\section{Sonuç}

Küreselleşme ile birlikte ekonomilerin birbiriyle olan sosyal, politik ve iktisadi entegrasyonu, beraberinde tüm ülkelerin ortak hareket etmesi gereğini ortaya çıkarmıştır. Literatürde sıklıkla vurgulanan tekil bir ulusal ekonomide meydana gelen reel veya finansal bir krizin tüm dünyaya etki etmesi örneğinde olduğu gibi, yine ulusal bir ekonomide ortaya çıkan işsizlik gibi iktisadi etkenler de diğer ülkeleri etkilemektedir. $\mathrm{Bu}$ nedenle küresel kamusal mallar arasında, ekonomik istikrar da sayılmakta; bunun aynı zamanda beyin göçü veya sosyo-politik nedenlerle birleşip kitlesel göçlere neden olduğu üzerinde durmaktadır. Dolayısıyla Küresel Keynesçilik yaklaşımında bahsedilen argümanlar, negatif dışsallıkların azaltılması açısından da ele alınabilir.

Literatürde çok az çalışmanın değindiği Küresel Keynesçilik, temel olarak, küresel talep yetersizliğinden kaynaklanan küresel mali istikrarsızlık ve küresel refahın azalması hususlarını ön plana çıkarmakta ve bu sorunların etkilerini en aza indirecek yöntemleri ortaya koymaktadır. $\mathrm{Bu}$ yöntemlerden küresel talebin artırılması, küresel paranın işlevi ve küresel istihdamın artırılması, bu çalışmada ele alınmıştır. Söz konusu yöntemler bir bütün olarak, genişleyici bir maliye politikası aktarım mekanizmasıyla ifade edilmiştir. Son olarak mevcut çalışma, günümüzdeki birkaç ülke örnekleminden hareketle, küresel talep ve küresel işsizlik gibi hususlar tahmin edilerek genişletilebilir. 


\section{Kaynakça}

Arslan, M. O. (2010), “Küresel Keynesçilik ve Küresel Ekonomik Kriz”. Ege Akademik Bakis 10/4, 1231-1242.

Bieler, A. (2013), Democratic global Keynesianism as a way out of crisis? Critical reflections on Heikki Patomäki's The Great Eurozone Disaster. Erişim Tarihi: Temmuz 10, 2019 http://andreasbieler.blogspot.com.tr/2013/09/democratic-global-keynesianism-asway.html.

Brand, U. (2006), “The World Wide Web of Anti-Neoliberalism: Emerging Forms of PostFordist Protest and the Impossibility of Global Keynesianism" içinde Neoliberal Hegemony. A global critic 236-251, ed. D. Plehwe et al. New York: Routledge.

Demmers, J., Jilberto, A. E. F., ve Hogenboom, B. (Eds.) (2004), Good governance in the era of global neoliberalism: conflict and depolitisation in Latin America, Eastern Europe, Asia, and Africa. Psychology Press.

Fontana, G. (2009), Whither New Consensus Macroeconomics? The Role of Government and Fiscal Policy in Modern Macroeconomics. The Levy Economics Institute WP no.563.

Galbraith, J. K. (1995), “Global Keynesianism in the wings?”. World Policy Journal, 12/3, 6569.

Hayter, T. (1981), The creation of world poverty. London: Pluto.

Köhler, G. (1998a), What is Global Keynesianism?. Erişim Tarihi: Temmuz 10, 2019 http://wsarch.ucr.edu/archive/papers/kohler/kohler2.htm

Köhler, G. (1998B), “The Structure of Global Money and World Tables of Unequal Exchange”. Journal of World-Systems Research 4, 145-168.

Köhler, G. (1999a), "Global Keynesianism and beyond”. Journal of World-Systems Research, 5, 252-274.

Köhler, G. (1999b), A Theory of World Income. Erişim Tarihi: Temmuz 10, 2019 http://wsarch.ucr.edu/archive/papers/kohler/KohlerWInc.html.

Patomäki, H. (2009), "Neoliberalism and the global financial crisis". New Political Science, 31/4, 431-442.

Patomäki, H. (2013), Resolving the Euro Crisis: Towards Democratic Global Keynesianism. $\begin{array}{llll}\text { Erişim } & \text { Tarihi: } & \text { Temmuz } & 10,\end{array}$ 
FSECON GÜLŞEN, M.A. ve GÖLÇEK, A.G. (2019), "Küresel Keynesçilik Yaklaşımı Bağlamında Küresel Maliye Politikalarl", Fiscaoeconomia, Vol.3(3), 98-109.

http://www2.euromemorandum.eu/uploads/patomaeki_resolving the_euro_crisis_tow ards_global_keynesianism.pdf.

Paul,J. (1996), The United Nations and Global Social-Economic Policy: Global Keynesianism for a New Era. Erişim Tarihi: Temmuz 10, 2019 https://www.globalpolicy.org/socialand-economic-policy/social-and-economic-policy-at-the-un/reform-of-ecosoc-and-thesocial-and-economic-policy-process-at-the-un/47425.html.

Sheppard, E., ve Leitner, H. (2010), "Quo vadis neoliberalism? The remaking of global capitalist governance after the Washington Consensus". Geoforum, 41/2, 185-194. 